\title{
Controle de fitopatógenos do solo com materiais vegetais associados à solarização.
}

\author{
Márcia Michelle de Queiroz Ambrósio ${ }^{1}$, César Júnior Bueno², Carlos Roberto Padovani³ ${ }^{3}$ Nilton Luiz de Souza ${ }^{4}$
}

${ }^{1}$ UFCG/CCTA/Unidade Acadêmica de Agronomia e Tecnologia de Alimentos, R. Cel. João Leite, 517, Cep. 58840-000, Pombal-PB; ${ }^{2}$ APTA/IBCEIB. Rodovia Heitor Penteado, Km 03, Jardim das Palmeiras, Caixa Postal 70, 13001-970, Campinas-SP; ${ }^{3}$ IBB/UNESP, Depto. Bioestatística, Botucatu - SP; ${ }^{4}$ In memorian.

Autor para correspondência: Márcia Michelle de Queiroz Ambrósio

Data de chegada: 24/09/2007. Aceito para publicação em: 01/09/2008

\section{RESUMO}

Ambrósio, M.M.Q.; Bueno, C.J.; Padovani, C.R.; Souza, N.L. Controle de fitopatógenos do solo com materiais vegetais associados à solarização. Summa Phytopathologica, v.34, n.4, p.354-358, 2008

A incorporação de material orgânico associada à solarização do solo é uma técnica promissora no controle de patógenos de plantas. O trabalho consistiu na prospecção de materiais vegetais promissores na produção de voláteis fungitóxicos capazes de inviabilizar as estruturas de resistência de fitopatógenos do solo. Em condição de campo foram incorporados $3 \mathrm{Kg} / \mathrm{m}^{2}$ de folhas e ramos de brócolos, eucalipto, mamona e mandioca brava, associada ou não à solarização, visando o controle de Fusarium oxysporum f. sp. lycopersici raça 2; Macrophomina phaseolina; Rhizoctonia solani AG-4 HGI e Sclerotium rolfsii. O controle foi avaliado por meio da sobrevivência das estruturas, em meios semi-seletivo específicos, aos 7, 14, 21 e 28 dias do início do experimento. Foram monitoradas as temperaturas do solo e do ar por um DataLogger Tipo CR23X (Campbell Scientific) e a porcentagem de $\mathrm{CO}_{2}$ e de $\mathrm{O}_{2}$ pelo equipamento analisador de gases (Testo 325-1). A associação da incorporação dos materiais vegetais com a solarização do solo inativou $F$. oxysporum f. sp. lycopersici raça 2, M. phaseolina e $R$. solani. O fungo $S$. rolfsii foi o único que não apresentou $100 \%$ de controle com solarização mais mamona durante o período estudado. A incorporação de mandioca seguido de solarização propiciou o controle de todos os fungos estudados com menos de sete dias da instalação do experimento, sendo tão eficiente quanto o brócolos na erradicação dos fitopatógenos veiculados pelo sol.

Palavras-chave adicionais: Solarização, matéria orgânica, fermentação acelerada, fungos fitopatogênicos, estruturas de resistência, controle.

\section{ABSTRACT}

Ambrósio, M.M.Q.; Bueno, C.J.; Padovani, C.R.; Souza, N.L. Control of soil-borne phytopathogenic fungi by the association between materials vegetable materials and solarization. Summa Phytopathologica, v.34, n.4, p.354-358, 2008

The association between previous incorporation of vegetable material and soil solarization is a promising technique for control of several phytopathogens. The objective of this work consisted in the investigation of materials vegetable that are promising to produce fungitoxic volatiles capable of inactivating the resistence structures of soil plant pathogens. Three $\mathrm{Kg} / \mathrm{m}^{2}$ of vegetable materials were incorporated under field conditions, and the survival of four fungal species (Fusarium oxysporum f. sp. lycopersici race 2; Macrophomina phaseolina, Rhizoctonia solani AG-4 HGI and Sclerotium rolfsii) was evaluated against four fresh materials vegetables, ground and incorporated into the soil (leaves and branches of broccoli, eucalyptus, castor bean, and wild cassava). Control was evaluated through of the analysis of the survival of structures in a specific semi-selective medium, during four periods ( 7 , 14, 21 and 28 days from the beginning of the experiment). Temperature values were monitored by a DataLogger Type CR23X (Campbell Scientific), and $\mathrm{CO}_{2}$ and $\mathrm{O}_{2}$ percentages were monitored with a gas analyzer equipment (Testo 325-1). The association between incorporation of vegetable materials with soil solarization inactivated $F$. oxysporum f. sp. lycopersici race 2, M. phaseolina and $R$. solani. The fungus $S$. rolfsii was the only that didn't present $100 \%$ of control with solarization more castor bean during the studied period. The incorporation of cassava followed by solarization provided the control of all fungi studied in less than seven days from the installation of the experiment, and was as efficient as broccoli in the eradication of these soil-borne plant pathogens.

Keywords: Soil solarization, organic matter, accelerated fermentation, phytopathogenic fungi,resistence strutures,control.

A solarização é uma das alternativas de controle para patógenos veiculados pelo solo (27). Há fitopatógenos para os quais a temperatura letal encontra-se acima daquela atingida pela solarização do solo. Além do fato de muitos destes organismos necessitarem de grandes períodos de exposição a altas temperaturas para inativá-los. A incorporação de material orgânico, previamente a colocação do plástico, promove o aprisionamento de gases fungitóxicos provenientes da decomposição acelerada, conferindo um efeito aditivo à solarização $(2,4,11)$. Esta situação propicia a inativação de fitopatógenos termotolerantes, bem como, reduz o período do tratamento. As brássicas possuem potencial como supressor de várias doenças causadas por patógenos do solo (3), pois libera em sua decomposição voláteis como ácidos orgânicos, aldeídos, enxofre, glucosinolatos, isotiocianatos, entre outros $(4,11,26,29)$. 
A mamona (Ricinus communis L.), mandioca (Manihot esculenta Crantz) e várias espécies de eucalipto (Eucalyptus grandis Hill ex Maiden) possuem em sua constituição compostos como óleos essenciais, terpineol, álcoois, aldeídos, terpenos, glicósidos, alcalóides, triterpenos, saponinas, flavonóides, taninos, glicosídeos cianogênicos que são descritos como inibidores de fungos $(7,23,25)$. Dessa forma, o presente trabalho consistiu na prospecção de materiais vegetais que produzam voláteis fungitóxicos capazes de controlar fungos fitopatogênicos veiculados pelo solo, em condições de solarização de solo a campo.

\section{MATERIAL E MÉTODOS}

O experimento foi conduzido entre outubro e novembro de 2004, com Fusarium oxysporum f. sp. lycopersici raça 2; Macrophomina phaseolina; Rhizoctonia solani GA-4 HGI e Sclerotium rolfsii frente a quatro materiais vegetais frescos [Folhas e ramos de brócolos (Brassica oleracea var. italica L); mamona (Ricinus comunis L.); mandioca (Manihot esculenta Crantz) e eucalipto (Eucalyptus grandis Hill ex Maiden)], os quais foram triturados e incorporados ao solo, na proporção de $3,0 \mathrm{Kg} / \mathrm{m}^{2}$.

Os fungos, provenientes da micoteca do DPV/FCA/UNESPBotucatu-SP, foram cultivados, inicialmente, em meio BDA (batatadextrose-ágar) + oxitetraciclina $(0,05 \mathrm{mg} / \mathrm{mL})$ e, posteriormente, transferidos para substratos específicos, objetivando produzir as estruturas de resistência. Para F. oxysporum f. sp. lycopersici raça 2 e S. rolfsii foi adotada a metodologia citada por Bueno (5). M. phaseolina e $R$. solani foram produzidos em frasco contendo substrato arenoorgânico, de acordo com a metodologia de Lefèvre e Souza (1993).

O experimento conteve 11 tratamentos, sendo dez deles em campo e um em laboratório. Cada tratamento em campo foi representado por cinco parcelas subdivididas de $6 \mathrm{~m}^{2}$ cada, sendo quatro destrutivas, que corresponderam às avaliações da sobrevivência dos fungos no tempo (7, 14, 21 e 28 dias), e uma onde foram monitorados os dados de temperatura e gases. Cada sub-parcela destrutiva continha oito bolsas de náilon, sendo duas (repetições) de cada fungo, contendo substrato com as estruturas de resistência.

Os tratamentos foram:

1- Solo com brócolos e solarizado; 2- Solo com eucalipto e solarizado; 3- Solo com mamona e solarizado; 4- Solo com mandioca e solarizado; 5- Solo com brócolos, não solarizado; 6- Solo com eucalipto e não solarizado; 7- Solo com mamona e não solarizado; 8- Solo com mandioca e não solarizado; 9- Solo sem material orgânico e solarizado; 10- Solo sem material orgânico e não solarizado; 11- Laboratório (referencial de sobrevivência de cada fungo).

A área experimental, localizada na latitude $22^{\circ} 51^{\prime} \mathrm{S}$ e longitude $48^{\circ} 26^{\prime} \mathrm{W}$ foi submetida a uma operação de gradagem realizada uma semana antes da instalação do experimento. Na data de montagem foi efetuado o nivelamento do solo.

Os materiais orgânicos foram colhidos e triturados em equipamento (DPM-500.1.2.4), utilizando-se de uma peneira com furos de $1 \mathrm{~cm}$ de diâmetro. A seguir, os materiais foram colocados em sacos plásticos e mantidos em câmara fria para serem incorporados no dia seguinte. A distribuição foi feita manualmente na superfície do solo, seguindo-se a incorporação com enxada rotativa acoplada a um trator, a $10 \mathrm{~cm}$ de profundidade.

As bolsas de tecido sintético (náilon), contendo cada uma 10 gramas do substrato infestado com estruturas de resistência dos fungos, foram amarradas com linha de náilon e fixadas etiquetas nas extremidades que ficaram à mostra na superfície do solo sob o plástico e nas testemunhas, para facilitar a sua localização e identificação. As bolsas foram enterradas no centro das sub-parcelas a $10 \mathrm{~cm}$ de profundidade, sendo distanciadas cerca de $20 \mathrm{~cm}$ entre si.

Os sensores de temperatura conectados a um coletor de dados modelo CR23X (Campbell Scientific), no qual foram registradas leituras diárias de temperatura, bem como sondas para coleta de gases (6) foram colocados a $10 \mathrm{~cm}$ de profundidade.

Posteriormente a colocação dos patógenos e equipamentos no solo, seguiu-se a aplicação dos filmes de polietileno de baixa densidade, transparente e aditivado (aditivo anti-ultravioleta) de $4 \mathrm{~m}$ de largura e $100 \mathrm{~mm}$ de espessura nas parcelas pré-determinadas. Não foi necessário irrigar a área uma vez que houve precipitação nos dias imediatamente anteriores à instalação do experimento.

As avaliações de sobrevivência dos fungos foram realizadas aos 0 , 7, 14, 21 e 28 dias após a instalação do experimento, por meio do plaqueamento em meio de cultura semi-seletivo. Para Fusarium, o meio foi o de Komada (16); para M. phaseolina o RB (9); o KHMP para $R$. solani (15) e BDA + oxitetraciclina para $S$. rolfsii (5). Nestes meios houve o desenvolvimento das colônias dos fungos a partir das estruturas, possibilitando assim a quantificação da sobrevivência dos fungos.

Após serem retiradas do solo, as bolsas com os fungos $M$. phaseolina, $R$. solani e $S$. rolfsii foram submetidas a uma desinfestação superficial para diminuir os contaminantes e possibilitar a contagem dos sobreviventes (5). Dez porções do substrato contendo as estruturas de resistência de M. phaseolina e R. solani e, no caso de $S$. rolfsii, dez escleródios, foram transferidos para cada uma das cinco placas (repetições) que, posteriormente, foram mantidas em BOD, à temperatura favorável para cada fungo. $\mathrm{O}$ substrato contendo $F$. oxysporum f.sp. lycopersici foi submetido a uma diluição seriada (quatro diluições) antes do plaqueamento (5).

Os dados do número de colônias de Fusarium e da porcentagem de sobreviventes de $M$. phaseolina, $R$. solani e $S$. rolfsii, considerando tratamentos e períodos de avaliação, foram analizados pela técnica da análise de variância não-paramétrica para o modelo com dois fatores, complementada com os respectivos testes de comparações múltiplas (30). O esquema de dois fatores foi analisado pelo procedimento nãoparamétrico pelo fato dos dados não possuírem distribuição gaussiana (normal) e os grupos serem heterocedásticos (variâncias desiguais). Os resultados foram apresentados por meio da mediana (medida de tendência central) e semi-amplitude total (medida de variabilidade).

\section{RESULTADOS E DISCUSSÃO}

A solarização aumentou as temperaturas máximas diárias em mais de $10^{\circ} \mathrm{C}$ (Figura 1). Provavelmente, o material orgânico associado à solarização contribuiu para o incremento dessa temperatura, devido ao processo acelerado de decomposição. A temperatura média das máximas obtida nesse experimento não atingiu $50{ }^{\circ} \mathrm{C}$. No entanto, foram observadas temperaturas máximas acima desse valor, principalmente nas parcelas incorporadas com material orgânico.

O tratamento que proporcionou um maior aumento na temperatura do solo, a $10 \mathrm{~cm}$ de profundidade, foi o brócolos mais solarização. A diferença da máxima temperatura média desse tratamento em relação ao tratamento com solarização foi de aproximadamente $5^{\circ} \mathrm{C}$. De acordo com Gamliel \& Stapleton (12), solos incorporados com compostos associados à solarização aumentam a temperatura de $2-3{ }^{\circ} \mathrm{C}$, comparando-se com aqueles apenas solarizados e esse adicional pode ser um importante fator de controle para organismos patogênicos. 
Temperaturas Máximas Diárias

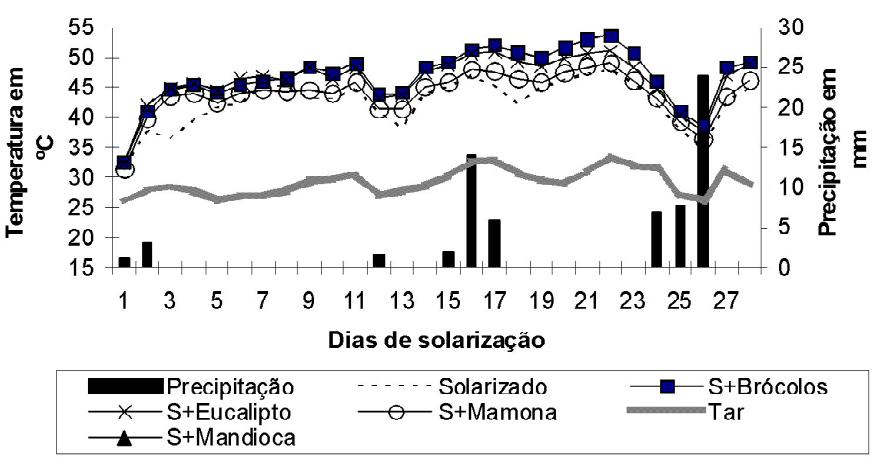

Figura 1. Efeito da incorporação de diferentes materiais vegetais associados ou não com solarização nas temperaturas máximas diárias do solo a $10 \mathrm{~cm}$ de profundidade. $\mathrm{S}=$ Solarizado; Tar $=$ Temperatura do ar.

A cobertura plástica propiciou aprisionamento do dióxido de carbono (ou gás carbônico) nos tratamentos onde houve associação de incorporação de material vegetal com solarização. Os tratamentos Solarizado + Eucalipto e Solarizado + Mandioca foram os que apresentaram maior concentração de dióxido de carbono (Figura 2).

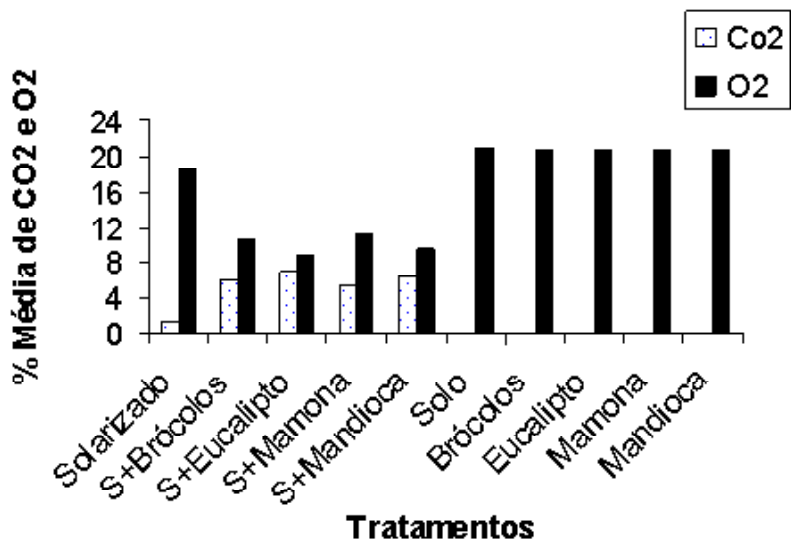

Figura 2. Efeito da incorporação de diferentes materiais vegetais associados ou não com a solarização na porcentagem média de gás carbônico $\left(\mathrm{CO}_{2}\right)$ e de oxigênio $\left(\mathrm{O}_{2}\right)$. $\mathrm{S}=$ Solarizado.

A inativação de $F$. oxysporum f. sp. lycopersici raça 2 ocorreu em todos os tratamentos em que associou-se a incorporação do material vegetal com a solarização. No entanto, os tratamentos com incorporação de brócolos, eucalipto e mandioca mais solarização não diferiram estaticamente entre si $(\mathrm{p}<0,01)$ quanto à inativação do fungo até $\mathrm{o} 7^{\circ}$ dia de tratamento. No tratamento onde se incorporou a mamona mais solarização, a erradicação do fungo só ocorreu entre os 21 e 28 dias de tratamento (Figura 3). Os gases liberados nos tratamentos citados, provavelmente, têm ação tóxica ao patógeno. Esse resultado está de acordo com Gamliel et al (10) que relatam à eficiência de controle de $F$. oxysporum f. sp. radicis-lycopersici, em tomate, através da combinação da incorporação de canola e solarização, destacando que esse patógeno é tolerante a altas temperaturas e que a solarização, por si só, não é eficiente no controle de doença causada pelo patógeno. O controle de $F$. oxysporum f. sp. aspargi associando à solarização com a incorporação de repolho foi relatado por Blok et al (4). Souza \& Bueno (28) obtiveram erradicação de clamidósporos de $F$. oxysporum f. sp. lycopersici raça 2 através da incorporação de couve e solarização no $14^{\circ}$ dia de tratamento. No trabalho de Souza \& Bueno (28) foram observadas menores temperaturas no solo do que no presente trabalho. Isto ocorreu porque houve muita precipitação no período do tratamento do trabalho de Souza \& Bueno (28). A aplicação do filme plástico é imprescindível para inativar o patógeno (Figura 3). Certamente, todos os materiais orgânicos devem liberar gases tóxicos aos fitopatógenos e, quando não há cobertura plástica, esses compostos são rapidamente dissipados para a atmosfera. Resíduos de eucalipto e mandioca brava incorporados ao solo seguido de solarização foram tão eficientes quanto às brássicas no controle de $F$. oxysporum f. sp. lycopersici raça 2. Possivelmente, compostos orgânicos voláteis como hidrocarbonetos, álcoois, aldeídos, cetonas, ácidos, ésteres em eucalipto (8), a ricinina na mamona (25) e o ácido cianídrico e a linamarina na mandioca (20), contribuíram positivamente para o controle desse fungo. Entretanto, não se sabe qual composto é o responsável pela toxicidade e inativação, bem como em que concentração os mesmos comportam-se como tóxicos a $F$. oxysporum f. sp. lycopersici raça 2.

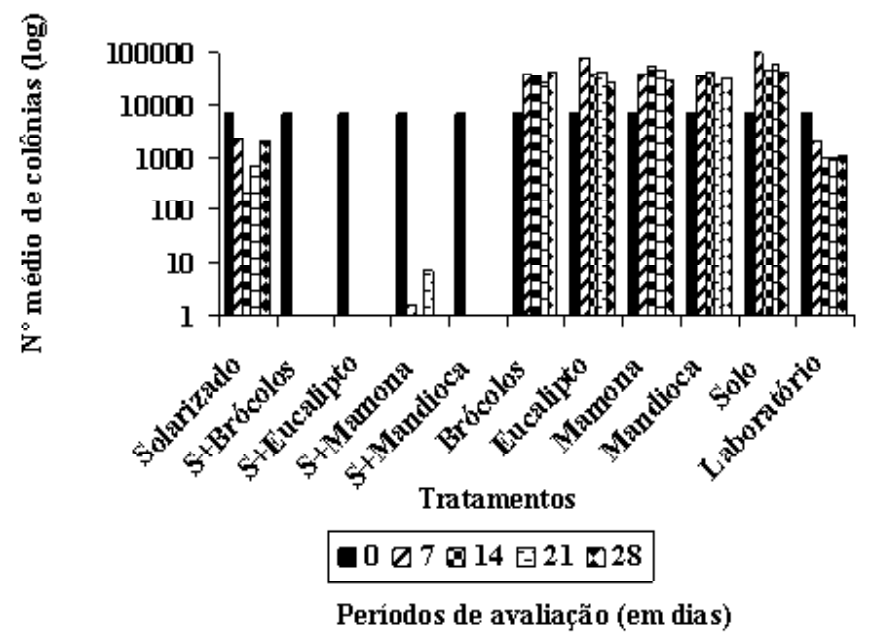

Figura 3. Efeito da incorporação de diferentes materiais vegetais associados ou não com a solarização na sobrevivência de Fusarium oxysporum f. sp. lycopersici raça 2 . $\mathrm{S}=$ Solarizado.

Os quatro materiais vegetais testados, associados à solarização, foram eficientes no controle de $M$. phaseolina (Figura 4). Os tratamentos com solarização mais incorporação de brócolos e mandioca não diferiram estatisticamente entre si ( $p>0,05)$ quanto ao controle do fungo desde a primeira avaliação da sobrevivência. No tratamento solarizado mais mamona, a erradicação do fungo ocorreu entre o $8^{\circ}$ e o $14^{\circ}$ dia de tratamento, enquanto que no tratamento solarizado+eucalipto, o controle já ocorreu entre o $22^{\circ}$ e o $28^{\circ}$ dia. Ambrósio et al (2) obtiveram controle de $M$. phaseolina quando incorporaram brócolos e solarizaram com três espessuras diferentes de polietileno. Quando esses autores utilizaram o plástico de $100 \mathrm{~mm}$ mais incorporação de brócolos obtiveram controle do fungo aos sete dias de tratamento. Lodha et al (18), trabalhando com associação da incorporação de resíduos de brássicas com a solarização, obtiveram erradicação de 75-96\% nos microescleródios de $M$. phaseolina. Os demais tratamentos foram ineficientes na erradicação do patógeno e nem mesmo diminuíram o número médio de colônias viáveis. Esse resultado corrobora com os dados obtidos por Ambrósio (1), Hartz et al (14), McCain et al (19) e Mihail \& Alcorn (21). A incorporação isolada dos materiais vegetais não teve reflexo no controle de M. phaseolina.

Os tratamentos em que foi incorporado material vegetal seguido 


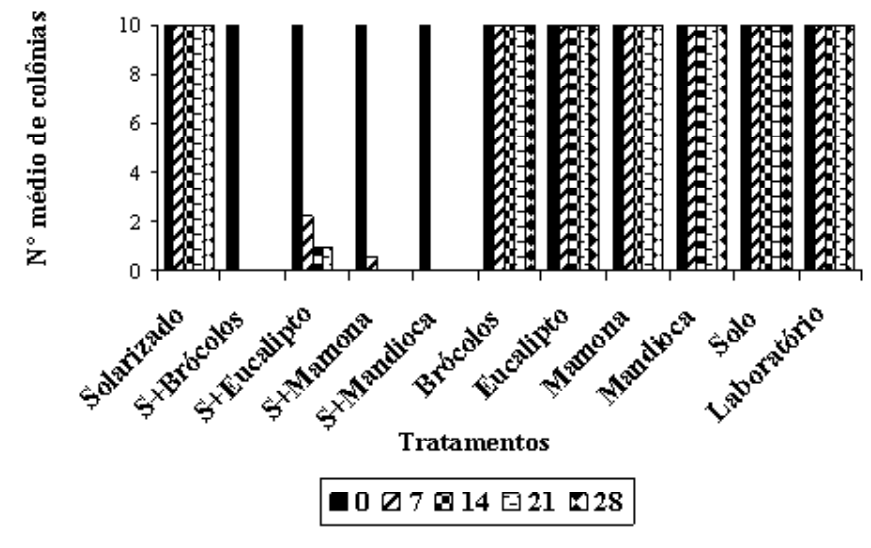

Períodos de avaliação (em dias)

Figura 4. Efeito da incorporação de diferentes materiais vegetais associados ou não com a solarização na sobrevivência de Macrophomina phaseolina. $\mathrm{S}=$ Solarizado.

por solarização do solo propiciaram a inativação de $R$. solani (Figura 5). Os tratamentos Solarizado+Brócolos; Solarizado+Mamona e Solarizado+Mandioca destacaram-se, pois erradicaram significativamente e de modo estatisticamente semelhante $(\mathrm{p}>0,05)$ as estruturas do patógeno, aos sete dias após a instalação do experimento. Na parcela em que se associou a incorporação de eucalipto com a solarização houve controle do fungo após o $14^{\circ}$ dia da instalação do experimento. Blok et al (4) também obtiveram significativa redução no número de estruturas de sobrevivência viáveis de $R$. solani quando incorporaram brócolos seguido de solarização do solo. Na parcela onde apenas foi aplicada a cobertura plástica não houve erradicação de R. solani. Entretanto, observou-se uma diminuição gradativa no número médio de colônias viáveis ao longo das avaliações. Blok et al (4) também não obtiveram erradicação de $R$. solani quando apenas aplicaram a cobertura plástica em dois anos consecutivos, mas os autores observaram uma redução na sobrevivência do patógeno no primeiro ano da solarização. Entretanto, esse resultado não se repetiu no ano seguinte. Existem divergências na obtenção de controle de $R$. solani através da solarização do solo, quando aplicada isoladamente (27).

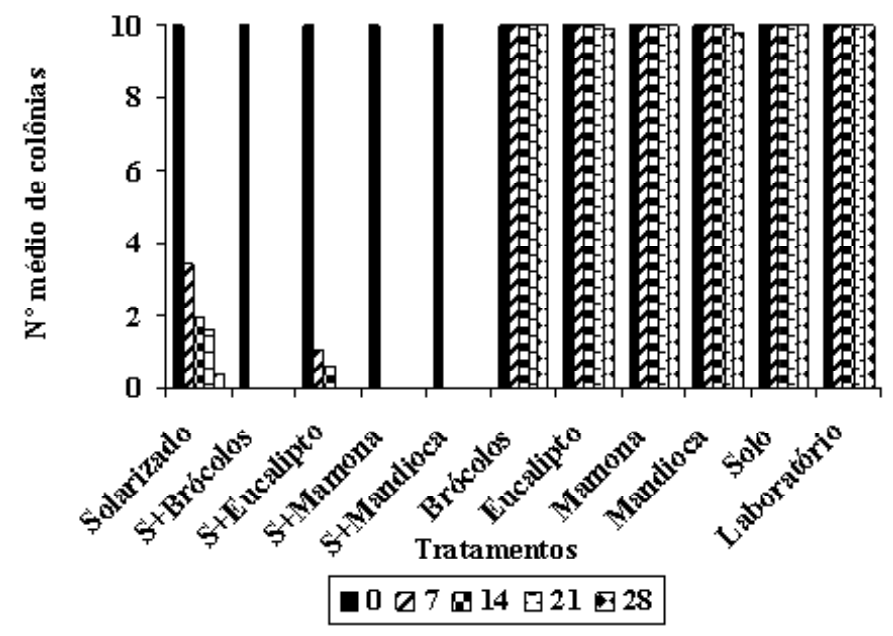

Períodos de avaliação (em dias)

Figura 5. Efeito da incorporação de diferentes materiais vegetais associados ou não com a solarização na sobrevivência de Rhizoctonia solani. $\mathrm{S}=$ Solarizado.
Patrício (22) estudou o efeito da solarização do solo em ambiente protegido e obteve a erradicação do fungo com 20 ou com 30 dias de tratamento, enquanto que na área externa do ambiente protegido, o fungo foi erradicado somente após 40 dias de solarização. De acordo com a autora, períodos de tratamento de 30 dias em casa de vegetação e de 40 dias em área externa, no verão, são suficientes para promover o controle do fungo. A incorporação isolada dos materiais vegetais (Figura 5) não erradicou R. solani, ficando claro que os compostos voláteis oriundos da decomposição do material orgânico e aprisionados pela cobertura plástica são os responsáveis pela eficiência na precocidade de controle de $R$. solani AG 4 HGI.

A eficiência da incorporação de brócolos, eucalipto e mandioca associados à solarização na erradicação de $S$. rolfsii pode ser verificada na Figura 6. A incorporação de mamona associada à solarização não erradicou o fitopatógeno, embora tenha sido observada uma significativa redução no número médio de colônias viáveis. Resultado semelhante foi obtido por Souza \& Bueno (28). O tratamento solarizado sem a incorporação de material vegetal não foi efetivo no controle de S. rolfsii, embora tenha havido uma diminuição no número médio de colônias viáveis (Figura 6). Esse resultado está em concordância com os dados obtidos por Souza \& Bueno (28), que também não obtiveram erradicação dos escleródios de $S$. rolfsii com solarização apenas.Muitos autores têm reportado a eficiência da incorporação de brássicas ao solo seguido de solarização no controle de diversos fungos fitopatogênicos $(2,4,11,18,24$ e 28), sendo que todos afirmam que o aprisionamento dos voláteis pelo filme plástico é o que confere a eficiência do tratamento. Esse fato também foi observado no presente trabalho com todos os materiais testados. Entretanto, Ghini et al (13), avaliando o efeito da solarização do solo no controle de $S$. rolfsii, em feijoeiro, obtiveram redução no número de escleródios recuperados nos dois ciclos da cultura, ainda que tenha sido alta a viabilidade destas estruturas. A temperatura máxima obtida por esses autores, na parcela solarizada, a $10 \mathrm{~cm}$ de profundidade, foi de $41^{\circ} \mathrm{C}$ e, de acordo com Lefèvre \& Souza (17), esta temperatura é subletal a $S$. rolfsii.

A incorporação de mandioca seguida de solarização erradicou significativamente todos os patógenos estudados aos sete dias da instalação do experimento, sendo esse material vegetal tão ou mais eficiente que as brássicas na erradicação dos fitopatógenos estudados.

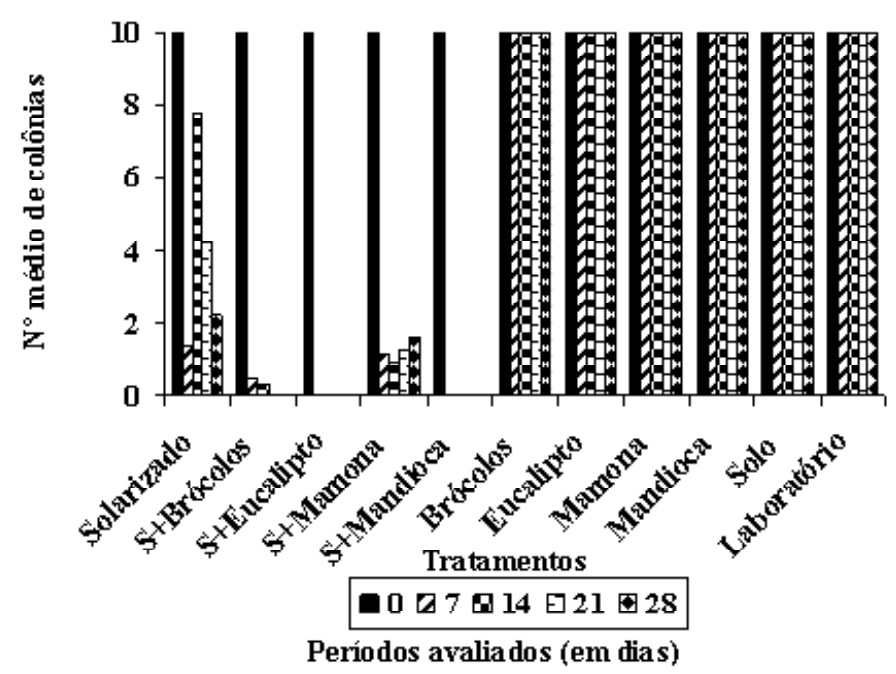

Figura 6. Efeito da incorporação de diferentes materiais vegetais associados ou não com a solarização na sobrevivência de Sclerotium rolfsi. $\mathrm{S}=$ Solarizado. 
Assim, fica evidente que a utilização da mandioca brava associada à solarização do solo no controle de doenças de plantas é conveniente e deve haver continuidade no estudo desse material. Pelos dados obtidos foi possível estabelecer uma lista ordenada por efetividade dos materiais promissores para serem utilizados com a solarização no controle dos patógenos estudados. Assim, tomando-se como referencial de eficiência o controle dos fungos com até sete dias de tratamento, seguem os seguintes materiais por ordem decrescente de efetividade:

1) Mandioca: F. oxysporum f. sp. lycopersici; M. phaseolina; $R$. solani e $S$. rolfsii;

2) Brócolos: F. oxysporum f. sp. lycopersici; M. phaseolina e $R$. solani;

3) Eucalipto: F. oxysporum f. sp. lycopersici e $S$. rolfsii;

4) Mamona: $R$. solani.

Os resultados demonstram que os materiais testados têm potencial no controle de fungos de solo, quando associados à solarização. Entretanto, cada material comporta-se diferentemente em relação aos patógenos estudados, necessitando pesquisas para determinar quais são os compostos letais gerados por esses materiais orgânicos e seus efeitos sobre os diferentes fitopatógenos.

\section{REFERÊNCIAS BIBLIOGRÁFICA}

1. Ambrósio, M. M. Q. Solarização no controle de patógenos e plantas invasoras nas culturas do tomateiro, feijoeiro e meloeiro. 2000, 26f. Monografia (Graduação) - Escola Superior de Agricultura de Mossoró, Mossoró-RN.

2. Ambrósio, M. M. Q.; Bueno, C. J.; Souza, N. L. Sobrevivência de Macrophomina phaseolina em solo incorporado com brócolos seguido de solarização. Summa Phytopathologica, Botucatu, v.30, n.3, p.364-370, 2004

3. Bettiol, W.; GhinI, R. Solos Supressivos. In: Michereff, S. J.; Andrade, D. E. G. T. Menezes, M. Ecologia e Manejo de patógenos radiculares em solos tropicais, 2005. p.125-143.

4. Blok, W.J., Lamers, J.G., Termorshuizen, A.J., Bollen, G.J. Control of soilborne plant pathogens by incorporating fresh organic amendments followed by tarping. Phytopathology, St. Paul, v.90, n.3, p.253-9, 2000.

5. Bueno, C. J. Produção e preservação de estruturas de resistência de fungos fitopatogênicos habitantes do solo. 2004, 101 f. Tese (doutorado) - Universidade Estadual Paulista/ FCA, Botucatu - SP.

6. Bueno, C. J \& Souza, N. L. Sonda para gases de subsolo. Summa Phytopathologica, Botucatu, v.28, n. 2, p.215 - 218, 2002.

7. Carvalho, V. D. \& Carvalho, J. G. Princípios tóxicos da mandioca. Informe Agropecuário, Belo Horizonte, v.5, n.59/60, p.82-88, 1979.

8. Charles, D.J.; Simon, J. E. Comparison of extraction methods for the rapid determination of essential oil content and composition of basil. Journal of American society of Horticultural Science, Alexandria, v.115, n.3, p.458-462, 1990.

9. Cloud, G. L. Comparison of three media for enumeration of sclerotia of Macrophomina phaseolina. Plant Disease, St. Paul, v.75, n.8, p.771-772, 1991

10. Gamliel, A.; Austerweil, M.; Kritzman, G. Non-chemical approach to soilborne pest management - organic amendments. Crop Protection, Oxford, v.19, p.847-853, 2000.

11. Gamliel, A., Stapleton, J. J. Characterization of antifungal volatile compounds envolved from solarizes soil amended with cabbage residues. Phytopathology, St. Paul, v.83, p.899-905, 1993 (a).

12. Gamliel, A., Stapleton, J. J. Effect of soil amendment with chicken compost or ammonium phosphate and solarization on pathogen control, rhizosphere microorganisms and lettuce growth. Plant Disease, St. Paul, v.77, p.886-891, 1993 (b).

13. Ghini, R.; Bettiol, W.; Caldari Júnior, P. Solarização do solo para o controle de Sclerotium rolfsii em feijoeiro. Summa Phytopathologica, Jaboticabal, v.23, n.2, p.143-145, 1997.

14. Hartz, T. K.; Carter, W. W.; BRUTON, B. D. Failure of fumigation and solarization to control Macrophomina phaseolina and subsequent muskmelon vine decline. Crop Protection, Surrey, v.6, p.261-264, 1987.

15. Ko, W.; Hora, F. K. A selective medium for Rhizoctonia solani in soil. Phytopathology, St. Paul, v.61, n.6, p.707-710, 1971.

16. Komada, H. Development of a selective medium for quantitative isolation of Fusarium oxysporum from natural soil . Review of Plant Protection Research, Tokyo, v.8, p.114-124, 1975.

17. Lefèvre, A. F.; Souza, N. L. de. Determinação da temperatura letal para Rhizoctonia solani e Sclerotium rolfsii e efeito da solarização sobre a temperatura do solo. Summa Phytopathologica, Jaguariúna, v.19, n.2, p.107-112, 1993.

18. Lodha, S.; Sharma, S. K.; Aggarwal, R. K. Solarization and natural heating of irrigated soil amended with cruciferous residues for improved control of Macrophomina phaseolina. Plant Pathology, London, v.46, p.186-190, 1997.

19. Mccain, H.; Bega, R. V.; Jenkinson, J. L. Solar heatings fails to control Macrophomina phaseolina from soil. Phytopathology, St Paul, v.72, p.985, 1982.

20. Midio, A. F.; Martins, S. I. Toxicologia de Alimentos. São Paulo: Varela, 2000, 295p.

21. Mihail, J. D.; Alcorn, S. M. Effects of soil solarization on Macrophomina phaseolina and Sclerotium rolfsii. Plant disease, St. Paul, 68, p.742-746, 1984.

22. Patrício, F. R. A. Solarização do solo em ambiente protegido e sua integração com controle biológico ou químico na viabilidade de Phythium aphanidermatum e Rhizoctonia solani. 2000. 89 f. Tese (Doutorado em fitopatologia) - Escola Superior de Agricultura Luiz de Queiroz, Piracicaba.

23. Plantas Tóxicas. Disponível em: <http:// aquabiotech2.tripod.com/id5.html> ACESSO em: 17 maio 2005.

24. Ramirez-Villapudua, J.; Munnecke, D. E. Control of cabbage yellows (Fusarium oxysporum f.sp. couglutinans) by solar heating of field soil amended with dry cabbage residues. Plant Disease, St. Paul, v.78, p.289-295, 1988.

25. Ribeiro, L. F.; Bedendo, I. P. Efeito Inibitório de extratos vegetais sobre Colletotrichum gloeosporioides - Agente causal da podridão de frutos de mamoeiro. Scientia Agrícola, v.56, n.4, p. 1267-1271, 1999.

26. Smolinska, U. Survival of Sclerotium cepivorum Sclerotia and Fusarium oxysporium clamydospores in soil amended with cruciferous residues. Journal Phytopathology, n.148, p.343-349, 2000 .

27. Souza, N. L. Solarização do solo. Summa Phytopathologica, Jaguariúna, v.20, n.2, p.3-15, 1994.

28. Souza, N. L. \& Bueno, C. J. Sobrevivência de clamidósporos de Fusarium oxysporum f. sp. lycopersici Raça 2 e Sclerotium rolfsii em solo solarizado incorporado com matéria orgânica. Summa Phytopathologica, Botucatu, v.29, n.2, p.153-160, 2003.

29. Subbarao, K. V.; Hubbard, J. C. Interactive effects of broccoli residue and temperature on Verticillium dahliae microesclerotia in soil and on wilt in cauliflower. Phytopathology, St. Paul, v. 86, n.12, p.1303-1310, 1996.

30. ZAR, J. H. Biostatistical analysis. Prentice-Hall, New Jersey, 1999, 663p. 